\title{
OPEN Light intensity regulates flower visitation in Neotropical nocturnal bees
}

\author{
Rodolfo Liporoni ${ }^{1 凶}$, Guaraci Duran Cordeiro ${ }^{1 凶}$, Paulo Inácio Prado ${ }^{1}$, Clemens Schlindwein ${ }^{2}$, \\ Eric James Warrant ${ }^{3 \otimes}$ \& Isabel Alves-dos-Santos ${ }^{1}$
}

The foraging activity of diurnal bees often relies on flower availability, light intensity and temperature. We do not know how nocturnal bees, which fly at night and twilight, cope with these factors, especially as light levels vary considerably from night to day and from night to night due to moon phase and cloud cover. Given that bee apposition compound eyes function at their limits in dim light, we expect a strong dependence of foraging activity on light intensity in nocturnal bees. Besides being limited by minimum light levels to forage, nocturnal bees should also avoid foraging at brighter intensities, which bring increased competition with other bees. We investigated how five factors (light intensity, flower availability, temperature, humidity, and wind) affect flower visitation by Neotropical nocturnal bees in cambuci (Campomanesia phaea, Myrtaceae). We counted visits per minute over 30 nights in 33 cambuci trees. Light intensity was the main variable explaining flower visitation of nocturnal bees, which peaked at intermediate light levels occurring 25 min before sunrise. The minimum light intensity threshold to visit flowers was $0.00024 \mathrm{~cd} / \mathrm{m}^{2}$. Our results highlight the dependence of these nocturnal insects on adequate light levels to explore resources.

Most bees are active during the day, especially under sunny and clear skies ${ }^{1}$. The ability to fly at low light intensities evolved at least 19 times independently. However, approximately $1 \%$ of the known bee species-ca. 250-are nocturnal, and the obligate dim-light taxa are distributed among the families Andrenidae, Apidae, Colletidae and Halictidae $^{2}$. These species forage in search of flowers in very low light intensities at night, between sunset and sunrise ${ }^{3,4}$. They include crepuscular bees that fly only during dawn and/or dusk, and truly nocturnal bees-such as the Paleotropical Indian carpenter bee Xylocopa tranquebarica ${ }^{5,6}$ - that also fly during night-time hours, which are defined by the time interval between the two astronomical twilight times at dusk and dawn ${ }^{2,4}$. Moreover, many Neotropical crepuscular bees forage under a dense rainforest canopy that reduces light levels by about 100 times $^{4}$ and may thus experience light intensities similar to those experienced at night in more open habitats. Therefore, nocturnal bees in general seem to be rare and have some relation to light levels in their environments.

According to several authors ${ }^{1,2,7-10}$, when compared with diurnal groups, we still know little about the basic biology of most nocturnal bees, especially concerning their behaviour and interactions with plants. The current knowledge refers mainly to nesting biology ${ }^{11-15}$, abundance and seasonality ${ }^{16}$, nocturnal activity hours ${ }^{17,18}$ and feeding resources ${ }^{9,15,19}$, especially in the genera Megalopta (Halictidae) and Ptiloglossa (Colletidae). Thus, many questions remain open, such as what environmental factors affect nocturnal bee activity, and especially how this activity is affected by light limitations.

The main factors that influence bee foraging activities are flower availability, temperature and light intensity, while relative air humidity and wind speed often play a secondary role ${ }^{20}$. Host flower abundance can positively affect the number of bees visiting a plant and their flower visitation rate ${ }^{21}$. Moreover, given that bees need to reach a minimum thoracic temperature to $\mathrm{fly}^{22}$, and avoid overheating during flight, foraging activity is determined by thermal constraints ${ }^{23}$. Finally, certain minimum light levels seem to be important for triggering first flights ${ }^{24-26}$. The relationships between these factors are complex and which factor is of greatest importance depends on the context $^{24-27}$. At night, temperatures and light levels are lower than during the day, and this could especially affect the behaviour of nocturnal bees ${ }^{2,28}$.

\footnotetext{
${ }^{1}$ Departamento de Ecologia, Instituto de Biociências, Universidade de São Paulo, Rua do Matão, travessa 14, São Paulo, SP 05508-900, Brazil. '2Departamento de Botânica, Instituto de Ciências Biológicas, Universidade Federal de Minas Gerais, Caixa Postal 486, Belo Horizonte, MG 31270-901, Brazil. ${ }^{3}$ The Lund Vision Group, Department Biology, University of Lund, Sölvegatan 35, 22362 Lund, Sweden. ${ }^{\square}$ email: rliporonid@gmail.com; guaradc@ gmail.com; eric.warrant@biol.lu.se
} 

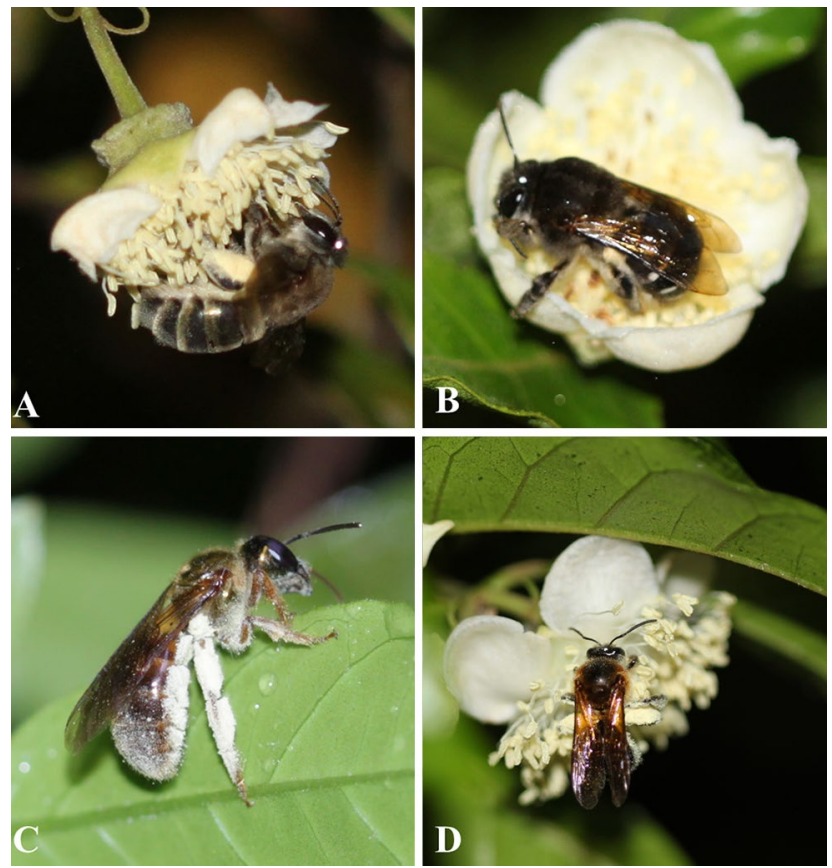

Figure 1. Nocturnal bee species that visit flowers of cambuci (Campomanesia phaea, Myrtaceae) in southeastern Brazil. (A) Ptiloglossa latecalcarata (Colletidae), (B) Ptiloglossa sp. (Colletidae), (C) Megalopta sodalis (Halictidae), (D) Megommation insigne (Halictidae).

Being able to navigate in dim light seems to be a major challenge faced by bees when foraging at night ${ }^{4}$. Light levels at night are up to 100 million times dimmer than those during the day, and all bees have apposition compound eyes, which are better adapted for brighter environments ${ }^{29}$. Insects that adopted a nocturnal lifestyle early in evolutionary history, such as most moths and many beetles, evolved superposition compound eyes whose optical design improves light capture by between two and three orders of magnitude compared to apposition eyes $^{4,30,31}$. In a typical apposition compound eye, such as found in bees, each ommatidium catches light from a given direction in space exclusively through its own small corneal lens (usually just a few tens of micrometres in diameter) and this tiny pupil limits the lowest light intensity for which vision remains reliable ${ }^{4,30}$. Thus, as light levels decrease after sunset, the apposition compound eyes of bees operate at their physiological limits ${ }^{4,30,32}$. Therefore, for nocturnal bees, their relatively recent evolutionary transition from a diurnal to a nocturnal lifestyle represented an invasion into a new and extreme environment ${ }^{32}$, where light intensity likely plays a major role in their foraging behaviour.

Nocturnal bees are likely to be more affected by light levels than by other environmental factors, not only because of the extremely low intensities of light at night, but also because of its immense daily variation, especially during twilight periods. During dusk or dawn, light intensity varies dramatically, since sun elevation changes very quickly, increasing light levels by at least one million times from night to day ${ }^{33,34}$. Moreover, twilight light levels can also change according to moon phase, moon elevation, cloud cover, and time in the season ${ }^{33,34}$. Thus, bee vision needs to cope with all this variation as well and foraging should be favoured in some, but not all, illuminations. Nonetheless, foraging during twilight and at night, despite these challenges, does have its advantages. Firstly, there is less competition, since most foraging bees are day-active ${ }^{9,35}$. Secondly, many plants bloom only at dawn or at night as a water-saving adaptation ${ }^{28}$. Thirdly, early morning bee foragers may be highly rewarded from unvisited flowers that have accumulated nectar throughout the entire night ${ }^{36}$. Thus, nocturnal bees could be favoured by foraging as early each day as possible. Considering the limitations in their ability to see at the dimmest nocturnal light levels, and their intense competition with a massive number of diurnal bees that start to arrive at flowers around sunrise when light levels are bright enough, we should expect a higher activity of nocturnal bees during the mid-twilight period, prior to the arrival of diurnal bees, when light intensities are at intermediate levels. During this period, nocturnal bees can still access flower resources earlier than other bees, but without compromising their visual capacities (as would have been the case at the dimmest nocturnal light levels). Therefore, during the dawn, foraging activity in nocturnal bees might increase as light levels rise, peak at intermediate twilight intensities, and fall as light levels continue to rise towards sunrise.

Nocturnal bees can pollinate Campomanesia phaea (O. Berg) Landrum (Myrtaceae), a tree species endemic to the Atlantic Forest of south-eastern Brazil and commonly known as cambuci. This plant reaches a height of $5 \mathrm{~m}$, blooms between October and January, and produces an acidic edible fruit ${ }^{37}$. Cambuci flowers are white, open at night, and release a sweet scent. Cambuci trees are mainly pollinated by nocturnal bees ${ }^{38}$ (Megalopta sodalis Vachal 1904, Megommation insigne Smith 1853, Ptiloglosssa latecalcarata Moure 1945, Ptiloglossa sp., and Zikanapis seabrai Moure 1953), which makes it an excellent study system for our investigation (Fig. 1). 


\begin{tabular}{|c|c|c|}
\hline Bee family & Bee species & Visitation rate $\left(\times 10^{-2}\right.$ visits $/$ flower $\left./ \mathrm{min}\right)$ \\
\hline \multirow{3}{*}{ Colletidae } & Ptiloglossa latecalcarata & $1.90 \pm 6.12$ \\
\hline & Ptiloglossa sp. & $0.03 \pm 0.66$ \\
\hline & Zikanapis seabrai & $0.002 \pm 0.15$ \\
\hline \multirow{3}{*}{ Halictidae } & Megalopta sodalis & $0.03 \pm 0.51$ \\
\hline & Megommation insigne & $0.17 \pm 1.39$ \\
\hline & Total & $2.13 \pm 6.46$ \\
\hline
\end{tabular}

Table 1. Visitation rate (mean \pm SD) of five nocturnal bee species foraging in a commercial cambuci (Campomanesia phaea, Myrtaceae) orchard surrounded by secondary Atlantic forest fragments in Mogi das Cruzes, São Paulo State, Brazil.

Here we investigate how light intensity affects the foraging activity of nocturnal bees on cambuci flowers. We also measure other environmental factors that could interfere with this relationship, such as flower availability, temperature, humidity and wind speed. Our hypotheses are: (1) light intensity is the main environmental factor that influences foraging activity in nocturnal bees, and (2) nocturnal bees are more active at intermediate light intensities in the twilight period. We also expect that foraging activity can start earlier on brighter nights, such as moonlit nights. Our findings demonstrate that the interaction between nocturnal bees and flowers strongly depends on light intensity. We discuss how this dependence can be explained by ecological requirements and evolutionary processes.

\section{Results}

We observed flowers for 7,614 min (or $127 \mathrm{~h}$ ) over 30 days during morning twilight. The beginning of the observation period varied from 5:12 h during the first twilight (17 October 2017) to 4:45 h during the last twilight (24 November 2017), while the end of the observation period varied from 6:59 h during the first twilight to $6: 39 \mathrm{~h}$ during the last twilight. This disparity reflects the variation in day length throughout the season, which resulted in an increase of $7 \mathrm{~min}$ in the total observation period from the first $(108 \mathrm{~min})$ to the last $(115 \mathrm{~min})$ twilight period.

Environmental factors. Light intensity levels varied in a predictable way during each twilight period, following a sigmoid curve. These levels were mainly controlled by sun elevation relative to the horizon (Fig. S1). Other environmental variables did not vary considerably within each twilight period but presented different average values for different twilight periods. Average air temperature ranged from $7.6{ }^{\circ} \mathrm{C}$ during the coldest twilight to $18.8^{\circ} \mathrm{C}$ during the warmest twilight (Figs. S2, S3). All twilight periods were very humid and with little wind, with average relative air humidity ranging from 89 to $100 \%$ (Figs. S4, S5) and maximum wind speed varying from 0 to $10.3 \mathrm{~km} / \mathrm{h}$ (Fig. S6). Orchard flower abundance increased as the flowering season advanced, from 109 to 640 flowers per day (Fig. S7). Therefore, light intensity, air temperature and flower abundance varied considerably among twilight periods, while relative air humidity and wind speed were less variable.

Visitation rate. The average number of visits per flower per minute for all twilight periods, and for the five species of nocturnal bees taken together, was $2.13 \pm 6.46 \times 10^{-2}$ (mean \pm SD), which were distributed in 33 cambuci trees (Table 1). Ptiloglossa latecalcarata, the most abundant species, had an average of $1.90 \pm 6.12 \times 10^{-2}$ (mean \pm SD) visits per flower per minute-approximately $90 \%$ of the total.

The visitation rate, on average, did not increase as the cambuci flowering season advanced and flower abundance increased $\left(r^{2}=0.03 ; y=0.0164+0.0003 x ; p=0.17\right.$; Fig. S8), mainly due to the relatively constant visitation rate of the most common bee P. latecalcarata (Fig. 1). Other nocturnal bee species had lower frequencies, with two species (Ptiloglossa sp. and Z. seabrai) recorded only in the last eight sampled twilight periods (Fig. S9).

During twilight, the visitation rate increased and reached a peak $25 \mathrm{~min}$ before sunrise, then decreased until $30 \mathrm{~min}$ after sunrise, when visits ceased. The visitation rate started to increase substantially during mid-twilight, when ambient light levels also started to increase (Figs. 2, S10). Most nocturnal bee species stopped foraging around sunrise, with the exception of $P$. latecalcarata, which was recorded until $30 \mathrm{~min}$ after sunrise (Figs. S11, S12). Diurnal bees, mostly worker bees of Apis mellifera (Apidae) and stingless bees (Meliponini), initiated flower visits around $30 \mathrm{~min}$ before sunrise (Figs. S13, S14).

Light intensity is the main factor affecting flower visitation rate of nocturnal bees in cambuci. The main environmental factor explaining cambuci flower visitation rate by nocturnal bees was light intensity. The model accounting for the effects of light intensity (with a quadratic term for light) was the best supported by the data, and no alternative model had an equivalent support (that is $\triangle \mathrm{AICc}<2$, Table 2), with the following equation for standardized variables: Visitation rate $=-2.94+0.44 \times$ (light intensity) $-1.60 \times($ light intensity $)^{2}-0.05 \times($ temperature $)+0.06 \times$ (humidity) $-0.07 \times($ wind $)+0.08 \times($ flowers $)$.

Model coefficients indicated that light intensity has a strong effect, while all other environmental variables exerted weak effects (Table S1). Light intensity had a standardized coefficient at least five times larger than the coefficient for the second most important variable (flower abundance). The $95 \%$ confidence intervals for estimated coefficients for temperature, relative air humidity, maximum wind speed, and orchard flower abundance included zero (Table S2). Therefore, only light intensity had a considerable and relevant effect on visitation rate. 


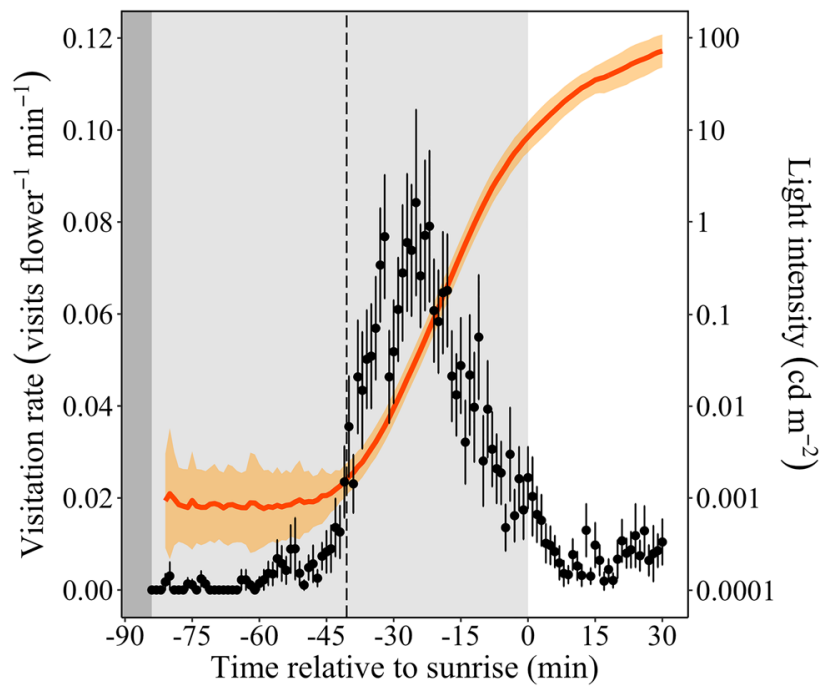

Figure 2. Visitation rate (visits/flower/min) by nocturnal bees on cambuci flowers and light intensity variation during twilight and for $30 \mathrm{~min}$ after sunrise. Black dots are average visitation rate values and black bars are standard errors of the mean ( $\mathrm{n}=30$ twilight periods). The coloured curve represents mean light intensity for each minute during twilight and the shaded area the relative errors $(\mathrm{n}=30$ twilight periods). Background colours represent true night (dark grey), twilight (light grey) and daytime (white). The vertical dashed line approximately marks mid-twilight. Sunrise time ( 0 in the time axis) varied between 6:29 h on the first sampled twilight (17 Oct 2017) to 6:09 h on the last twilight (24 Nov 2017).

\begin{tabular}{|l|l|l|l|l|c|}
\hline Models & logLikelihood & AICc & AAICc & DF & Weight \\
\hline Light + light ${ }^{2}$ all other variables & $-3,645.5$ & $7,309.1$ & 0.0 & 9 & 1 \\
\hline Light + all other variables & $-4,379.6$ & $8,775.1$ & $1,466.1$ & 8 & $<0.001$ \\
\hline All variables, except light & $-4,381.0$ & $8,775.9$ & $1,466.9$ & 7 & $<0.001$ \\
\hline No fixed effects (null) & $-4,670.4$ & $9,342.7$ & 2033.6 & 1 & $<0.001$ \\
\hline
\end{tabular}

Table 2. Model selection for factors affecting foraging activity of nocturnal bees, using generalized linear mixed models (GLMMs) with Poisson distribution. AICc corrected Akaike information criterion, DF degrees of freedom. The response variable was the number of visits per minute, using the number of observed flowers as model offset. The best model includes all environmental variables (light intensity, air temperature, relative air humidity, maximum wind speed, orchard flower abundance) with a quadratic term for light intensity.

We also found that visitation rate peaks at intermediate light intensity levels (Fig. 3), as we expected. According to the best supported model, at a medium light intensity of $0.01 \mathrm{~cd} / \mathrm{m}^{2}$ nocturnal bees would make 32 times more visits per flower per minute than at the lowest light level of $0.0001 \mathrm{~cd} / \mathrm{m}^{2}$ and 24 times more visits per flower per minute than at the highest light level of $100 \mathrm{~cd} / \mathrm{m}^{2}$. The lowest light level that nocturnal bees began to forage in cambuci flowers was recorded as $0.00024 \mathrm{~cd} / \mathrm{m}^{2}\left(\right.$ or $\left.2.4 \times 10^{-4} \mathrm{~cd} / \mathrm{m}^{2}\right)$.

From the selected model, we also noted that brighter nights, i.e., those with higher light levels during the first half of the twilight (Fig. S1), permit earlier visits. The earliest measured light intensity levels on brighter nights (e.g. those with a full moon), which were around $0.003 \mathrm{~cd} / \mathrm{m}^{2}$, were responsible for this increased visitation activity. On darker nights the earliest measured light intensity levels were much dimmer-around $0.0003 \mathrm{~cd} / \mathrm{m}^{2}$ (see the response of visitation rate to these light intensity levels in the red curve in Fig. 3). Indeed, nights with earlier bee activity seem to be brighter nights (Fig. 4), if we take into account the average light intensity during the first half of the twilight, when light levels varied substantially among twilight periods (Fig. S1).

\section{Discussion}

The foraging activity of nocturnal bees in cambuci flowers during morning twilight can be predicted mainly by light intensity, and other putative environmental factors do not contribute as much to these predictions. The maximum activity occurs at intermediate light intensity levels (around $0.1 \mathrm{~cd} / \mathrm{m}^{2}$ ), which usually occur around $30 \mathrm{~min}$ before sunrise. The onset of activity occurs at a minimum light intensity threshold of $0.00024 \mathrm{~cd} / \mathrm{m}^{2}$, which is one of the first recorded thresholds for flower foraging in nocturnal bees (see below). For twilight periods with higher initial light intensity levels, such as during clear moonlit nights, nocturnal bees can start to forage earlier. This light-dependent foraging activity is likely related to a combination of factors, such as visual challenges imposed by dim light levels ${ }^{31}$ and ecological demands to access resources before the onset of visits made by massive numbers of diurnal bees ${ }^{35}$. 


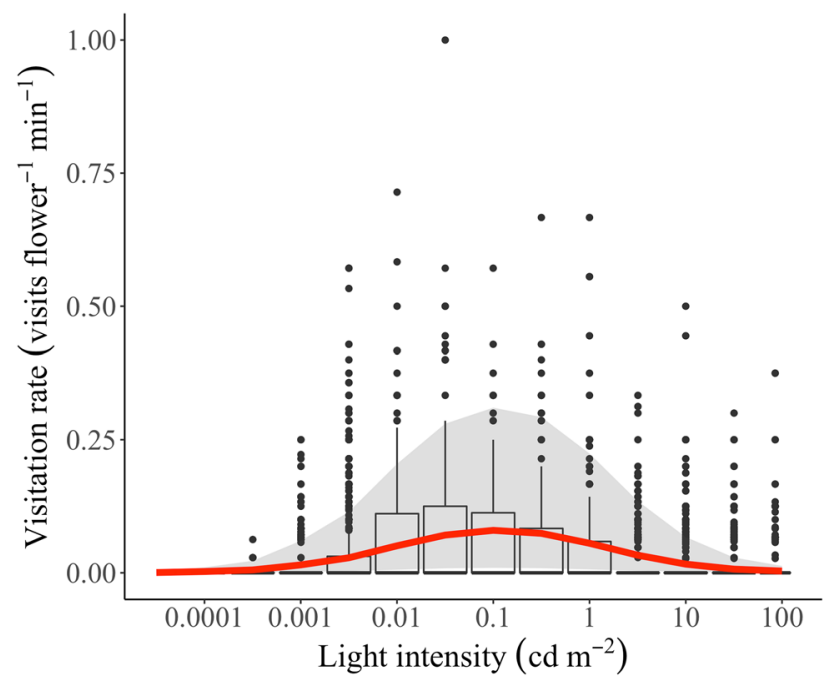

Figure 3. Distribution of visitation rate (visits/flower/min) by nocturnal bees on cambuci flowers during twilight as a function of light intensity measured as luminance $\left(\mathrm{cd} / \mathrm{m}^{2}\right)$. Boxes delimit where $50 \%$ of the values for each light interval are concentrated, horizontal lines indicate the median (all of them are zero), and dots represent outliers. The red curve represents the predicted visitation rate by the best supported model, which includes a quadratic term for the light effect. The $95 \%$ confidence interval of predicted values is shown in light grey.

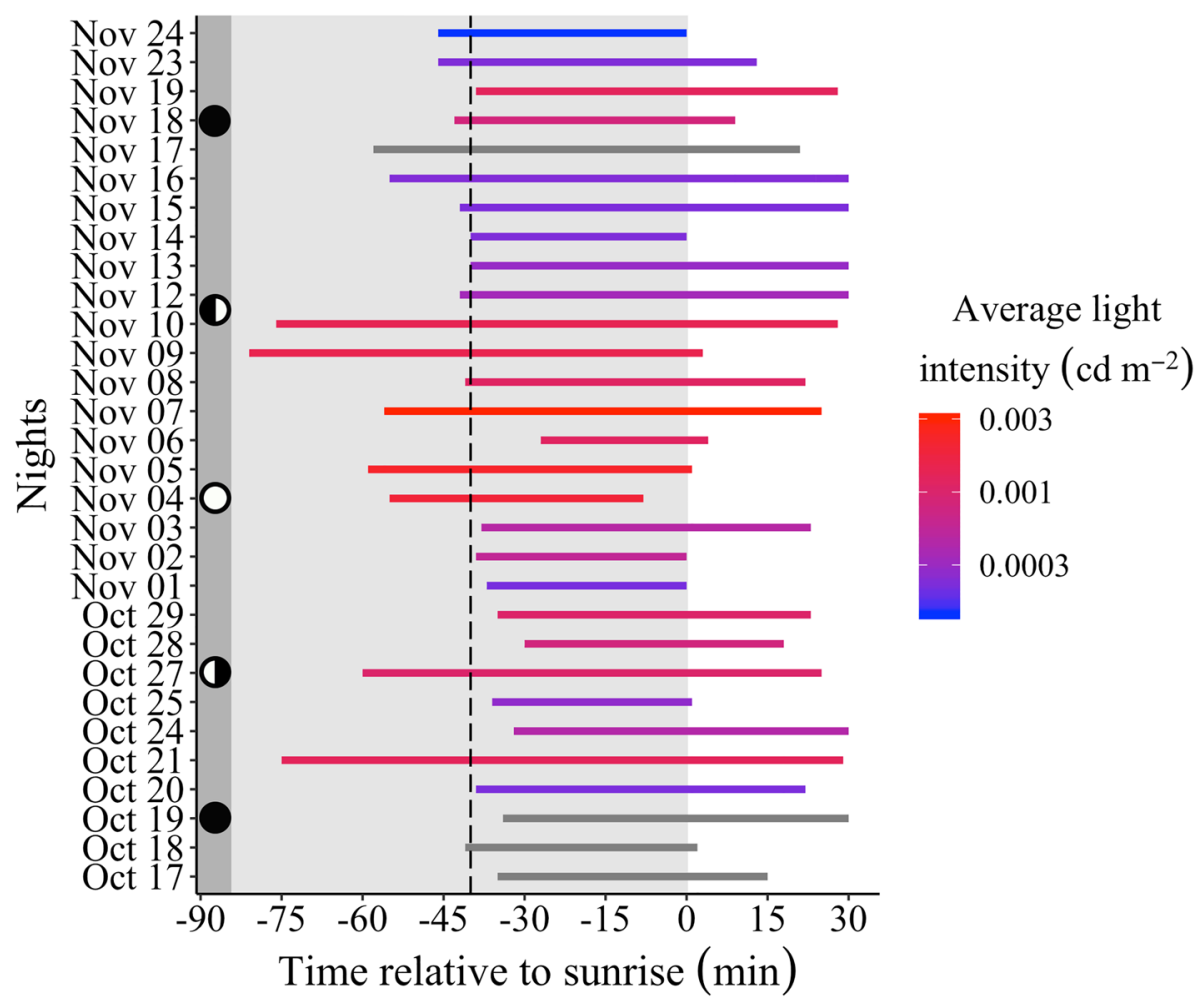

Figure 4. The activity durations of nocturnal bees foraging on cambuci flowers measured during twilight periods over five weeks. Each horizontal line represents the time interval during which bees visited cambuci during each twilight period. Line colours indicate average light intensity-measured as the average luminance of an $18 \%$ grey card $\left(\mathrm{cd} / \mathrm{m}^{2}\right)$ during the first half of the twilight when light levels varied considerably between twilight periods (see this variation in Fig. S1). Grey horizontal lines are nights with missing light intensity data from the first half of the twilight. Circles at left represent moon phases (new moon=black circle; full moon $=$ white circle). Other plot conventions as in Fig. 2 . 
It makes sense that light intensity controls nocturnal bee activity because dim light environments represent an extreme situation for bees, which are equipped with apposition compound eyes that are better adapted for brighter conditions $s^{4,32}$. We thus expected that the visual capacities of nocturnal bees-and thus their flight and foraging activities-require a minimum light level. Indeed, this threshold exists for other nocturnal species. According to a previous study ${ }^{39}$, a light intensity of at least $0.0001 \mathrm{~cd} / \mathrm{m}^{2}$-about half of the threshold we found here-is required for foraging activity in Megalopta genalis (Halictidae), a bee inhabiting rainforests, while for Lasioglossum (Sphecodogastra) lusoria (Halictidae), a bee inhabiting deserts, a light level of at least $0.02 \mathrm{~cd} / \mathrm{m}^{2}$ is required. In the present study, we provide a minimum light intensity that nocturnal bees require to find flowers in an agro-forest context, where shadows from taller neighbouring trees reduce light levels even more. Our threshold intensity value thus agrees well with that previously reported for M. genalis when flying in forests ${ }^{39}$, indicating that nocturnal bees foraging on cambuci likely have a similar light intensity threshold. The registered minimum threshold of $0.00024 \mathrm{~cd} / \mathrm{m}^{2}$ is, surprisingly, approximately 100 times dimmer than the value registered for the desert bee L. lusoria foraging in Onagraceae plants ${ }^{39}$. This finding confirms our previous understanding concerning the dimmest conditions in which nocturnal bees can find flowers in general, especially in darker environments such as forests. Thus, our results demonstrate that foraging activity is limited by light intensity and can occur in extremely dim conditions. Moreover, our study confirms the importance of measuring actual light levels in situ rather than using arbitrary descriptors such as "nocturnal", "crepuscular" or "diurnal" when comparing the behaviours of bees that are dependent on light intensity.

Our results also show that light intensity influences the activity of nocturnal bees in a non-linear manner, contrasting with what we know for diurnal bees ${ }^{1,40}$. Many studies have demonstrated how light intensity affects the onset of foraging activity in diurnal bees ${ }^{24,25,41,42}$. It is generally stated that light controls bee activity in a linear way (based on simple linear regressions) ${ }^{40}$, and consequently, cloudy days should delay the onset of bee activity, and this has been confirmed for several species of solitary and social bees ${ }^{24-26}$. However, this is not the case for the nocturnal bees studied here. These bees still have a strong light-dependent activity, but bee activity peaks at intermediate light levels and then falls as light levels increase even more.

This difference in light-dependent activity between nocturnal bees and diurnal bees begs explanation. Why should higher light intensities following sunrise actually decrease the activity of nocturnal bees? We propose two non-exclusive explanations: one physiological and one ecological. First, nocturnal bees probably have an endogenous clock that sets the exact times to start and to stop foraging, as already demonstrated for other bee species $^{43,44}$. By using environmental cues such as light intensity to entrain their circadian rhythm ${ }^{45}$, bees could predict the best time to cease collecting resources and to start investing in activities within the nest. Second, higher light levels trigger (or coincide with) the arrival of diurnal bees in cambuci flowers, possibly stimulating nocturnal bees to stop their foraging activity to avoid competition. During evolution, nocturnal bees might have changed their preferred foraging period from daytime to night-time to avoid competition and to inhabit a niche relatively free of enemies ${ }^{2}$. This hypothesis was tested for two Neotropical nocturnal bee species in PanamaMegalopta genalis and M. ecuadoria (Halictidae) - and it was found that nest parasitism rates for these species were four times lower than those of closely related diurnal species ${ }^{9}$. Moreover, there is evidence that interference competition with diurnal bees causes Megalopta to cease foraging activity in the morning ${ }^{35}$. We have also observed that diurnal bees, mainly Apis mellifera, arrive in large numbers just before sunrise and occupy all the space in cambuci flowers (Figs. S13, S14), which likely deters the activity of nocturnal bees. Therefore, our results support the idea that higher light intensities can be used as a proxy for the end of an activity regulated by a circadian clock and/or an increased competition with diurnal bees, since higher light levels do not prevent nocturnal bees from continuing to see their surroundings (Eric Warrant, personal observation). Indeed, nocturnal bees cease visiting cambuci flowers at light levels of around $100 \mathrm{~cd} / \mathrm{m}^{2}$, which occurs about $30 \mathrm{~min}$ after sunrise, the time which coincides with many diurnal species, especially social bees, on cambuci flowers ${ }^{38}$ (Figs. S11, S12).

Another interesting result we obtained is that light intensity is the main (and perhaps the only) factor controlling the activity of nocturnal bees. Considering that diurnal bees also frequently respond to temperature and flower availability ${ }^{24,27}$, why did flower availability not affect substantially visitation rates in our nocturnal bees? As previously stated, a nocturnal lifestyle brings some advantages for accessing resources prior to potential diurnal competitors ${ }^{9}$, so variations in flower availability might not affect the activity of nocturnal bees as much as it would for the considerably more numerous diurnal bees. Moreover, in our agro-forest context, bees were foraging within a high density of cambuci trees-their apparent main source of pollen-over a relatively small area. This represents a highly artificial condition, since cambuci trees are very likely to be sparser in their natural habitats. For these two main reasons, floral resources were probably not limiting for these bees.

Finally, why did temperature not considerably affect the activities of nocturnal bees on cambuci flowers? As far as we know, only four studies ${ }^{46-49}$ have evaluated the effects of temperature on the activities of nocturnal bees. Two of these studies ${ }^{46,49}$ found no effect of temperature, while one study suggests that temperature positively affects bee activity, but only above $25^{\circ} \mathrm{C}$ and combined with lower light intensity ${ }^{47}$. The fourth study found that higher temperatures have a moderately negative effect on activity ${ }^{48}$. Thus, on its own temperature seems to have only a weak to moderate effect on nocturnal bee activity. Moreover, three of the studies also suggest light intensity as a factor affecting bee activity ${ }^{46-48}$. Our study appears to be the first to evaluate how several factors simultaneously affect nocturnal bee activity on a fine scale (i.e. over intervals of one minute) and to determine the exact relation, in terms of magnitude and direction, between environmental variables and the foraging activity of nocturnal bees. Hence, it seems that light intensity affects the activity of nocturnal bees in general, but that the effect of temperature is secondary and varies according to context.

As temperature is relatively constant in tropical environments ${ }^{28}$, light could be the only determining factor for foraging times in Neotropical nocturnal bees. Even though our nocturnal bees did not experience constant temperature-which varied from approximately 8 to $19^{\circ} \mathrm{C}$-bees were able to visit flowers even on the coldest night. This suggests that these low temperatures are not an obstacle for foraging and that perhaps these bees 
might thermoregulate. Many desert bees have a bimodal activity pattern similar to nocturnal bees and are notably able to overcome low temperatures early in the morning and to avoid overheating in the hottest hours of the day and are thus classified as endothermic animals ${ }^{50}$. For instance, the desert bee Ptiloglossa arizonensis can fly very early on cold days and, once in the air, this bee can keep higher thoracic temperatures than its surroundings ${ }^{46}$. This probably explains why the foraging behaviour of our bee Ptiloglossa latecalcarata, which is closely related to $P$. arizonensis and likely to have the same thermoregulatory capacities, depends very little on temperature.

Besides using vision, nocturnal bees can also use other sensory information to find flowers in the dark, such as floral volatiles ${ }^{51,52}$. In cambuci flowers, 2-phenylethanol and 1-octanol are the two main compounds, which are preferentially emitted at night, soon after anthesis ${ }^{38}$. However, bees still depend heavily on visual cues to learn the characteristics of the first flowers they encounter and to land on them ${ }^{53}$. Relative to the dark green background of cambuci leaves, cambuci flowers are incredibly bright, with a broad reflection spectrum that likely creates a high contrast white target for a nocturnal bee (Fig. S15). Combining these previous results on scent-mediated flower visitation ${ }^{38,51,52}$ with our findings of a minimum light intensity threshold that permits flower search behaviour (and reflection spectra indicating that cambuci flowers have likely evolved to be highly salient visual targets at night), we suggest that nocturnal bees use both vision and olfaction to find flowers. Diurnal bees combine visual and olfactory cues to recognize and find flowers ${ }^{54,55}$, and our work indicates that this is likely the case for nocturnal bees too. Moreover, these two floral sensory cues seem to be correlated in a community context and when integrated together could enhance bee attraction and pollination ${ }^{56}$. Thus, it would be worthwhile to investigate how nocturnal bees specifically respond to various floral visual cues and how they integrate information from different sensory modalities (e.g. vision and olfaction) during foraging, especially in a community-wide perspective.

In conclusion, light intensity is the main environmental factor affecting the foraging activity of nocturnal bees on cambuci flowers. Their activity during the morning twilight peaks at intermediate light intensity levels, implying that brighter nights, with higher light levels in the first half of the twilight, permit earlier foraging activity. These findings highlight the environmental factors that are relevant for explaining the interaction between nocturnal bees and their host plants. Our results also show that the light-dependent activity of bees is not always linear (as found in many diurnal species). In the case of nocturnal bees, this non-linear activity might be explained in terms of evolutionary advantages to forage earlier, associated with an endogenous clock that possibly sets the time to stop foraging and/or prevents competition from diurnal bees at higher light levels. Intriguing questions that remain for further study include how the different senses used by bees to find flowers (such as olfaction) interact with this light-dependent activity, and how bees, including diurnal species, are affected by ambient light intensity in other contexts.

\section{Methods}

Study area. Field work was conducted on private farmland (Sítio Cambuci Nativa, $23^{\circ} 25^{\prime} \mathrm{S}, 46^{\circ} 10^{\prime} \mathrm{W}$, $670 \mathrm{~m}$ a.s.l.) in Mogi das Cruzes, São Paulo State, Brazil (Fig. S16). The 15-ha farm is located within the Atlantic Forest domain and includes cambuci tree orchards (6 ha) and secondary forest fragments $(9 \mathrm{ha})$. According to an updated Köppen-Geiger classification, the regional climate is type Cfa, humid subtropical, with a hot summer and average annual rainfall over $1,400 \mathrm{~mm}^{57}$.

Study system. Cambuci trees exhibit steady-state flowering, producing few new flowers per day. The hermaphroditic disc flowers measure around three centimetres in diameter, have white petals (Fig. S15) and up to 500 stamens, and offer only pollen as reward ${ }^{38}$. Flowers last only one day and open during the night, between 4:00 and 4:30 h. They are visited by a large diversity of insects, such as wasps, flies and bees, including diurnal and nocturnal bees ${ }^{38}$. The insects visit the flowers at different times of the day: nocturnal bees initiate visits soon after the beginning of anthesis and leave the flowers at sunrise or some minutes later, being followed by diurnal floral visitors until noon, when most of the pollen has already been depleted. However, nocturnal bees are the most effective pollinators ${ }^{38}$.

In the study area, five nocturnal bee species were sampled visiting the flowers of C. phaea: Megalopta sodalis (Halictidae), Megommation insigne (Halictidae), Ptiloglosssa latecalcarata (Colletidae), Ptiloglossa sp. (Colletidae), and Zikanapis seabrai (Colletidae) (Fig. 1; Table 1). Bees of Megalopta nest in dead wood ${ }^{14}$, while the other species nest in the soil ${ }^{15,58}$. Colletid species are solitary, while the halictid species are facultatively social ${ }^{1,14}$.

Flower visitation rate. We counted flower visits per minute to measure bee foraging activity during the morning twilight. Also called dawn in its final part, this period begins at astronomical twilight when the sun is $18^{\circ}$ below the horizon and starts to contribute to light levels in the atmosphere (ending true night) and finishes when the sun rises ${ }^{33}$. We also recorded flower visits per minute from sunrise until $30 \mathrm{~min}$ after sunrise (when sun elevation is around $6^{\circ}$ above the horizon and light intensity reaches a stable value), since nocturnal bees can extend their activity some minutes after sunrise on some days. We counted visits over 30 days, from October to November 2017, covering half of the cambuci flowering season. As twilight duration increases as the summer solstice approaches ${ }^{59}$, the total observation time per twilight period ranged from 108 to $115 \mathrm{~min}$. We did not sample on rainy mornings, since rain limits bee activity and imposes technical limitations on measuring light levels.

During each night, before twilight and anthesis, two or three observers randomly selected one tree each, totalling two or three flowering cambuci trees per night. When the selected tree was not flowering, we moved along the planting line from east to west until a flowering individual was found. Each observer selected a number of flowers to watch during each twilight (average of 12 observed flowers per tree, varying from 4 to 37, according to the number of flowers in the field of view) and stayed close to the tree waiting for bees with their head 
lantern turned off. When one bee was heard, we turned lanterns on for a few seconds to register the bee species. We recorded, according to the local time, the exact minute of each visit and the bee species observed. Later, we organized raw data as the number of visits for different bee species each single minute. We calculated the flower visitation rate (number of visits per observed flower per minute) as our response variable and discriminated between each tree and each night. We also counted visits from diurnal bee species since they started to arrive when nocturnal bees were still active (Supplementary Information).

Measurements of environmental factors. Light intensity was measured as luminance $\left(\mathrm{cd} / \mathrm{m}^{2}\right)$ of light reflected from an $18 \%$ grey card using a very sensitive (measurement range: $0.00001-19.90 \mathrm{~cd} / \mathrm{m}^{2}$ ) photometer (ERP-105, Hagner, Sweden) coupled to a data logger (OM-CP-VOLT101A, Omega, Brazil; sample rate: $0.2 \mathrm{~Hz}$ ). Average light intensity per minute was recorded from the data logger and light data were measured for the entire observation period. The photometer was placed in an open area $10 \mathrm{~m}$ away from the orchard border to avoid interference from observers' lanterns (Fig. S16).

Other abiotic factors that could potentially affect bee activity were also measured to control their effects and to better discriminate the effect due to light intensity only. Air temperature and relative air humidity were measured each night with a thermohygrometer (HOBO-U23-001, Onset, USA) installed at flower level in one of the observed cambuci trees. We also measured these climate variables with a meteorological station (H21-USB, Onset, USA) installed in an open area 70-100 m away from the orchards (Fig. S16). We measured maximum wind speed for the entire observation period with a portable cup anemometer (PCE-A420, PCE Instruments, Germany) installed close to the photometer. All devices were equipped with data loggers, and visitation data could be compared with environmental factors minute by minute. We also qualitatively estimated cloud cover in the sky; twenty nights had completely overcast skies while ten were clear starlit nights. Weather conditions were relatively constant throughout the duration of each observed twilight.

Flower availability was estimated as flower abundance in two ways: (1) the total number of recently open flowers in 20 randomly selected cambuci trees each night (orchard flower abundance); and (2) the total number of recently opened flowers in the selected trees (tree flower abundance). We randomly selected 20 different individual trees from which to count flowers after the end of the observation period and repeated the selection each night to detect daily floral resource variation. We counted all recently opened flowers in a tree following branches from bottom to top.

Data analyses. To evaluate how light intensity affects the activity of nocturnal bees when controlling for other environmental factors, we modelled visit count data using generalized linear mixed models (GLMMs) with a Poisson distribution, and included the number of observed flowers per tree as an offset. All models included the additive effects of environmental factors (light intensity, temperature, humidity, wind speed, and flower abundance) as predictor variables (fixed effects) and an identifier of the tree and the sampling night as possible random effects to account for shared variance of nested sampling units.

Prior to modelling, we standardized all candidate fixed-effect variables and excluded those that were highly correlated $(r h o>0.5)$. Thus, we kept only temperature and humidity variables from the meteorological station and only orchard flower abundance estimates, excluding temperature and humidity data from thermohygrometer and tree flower abundance. All analyses were implemented in the $\mathrm{R}$ environment ${ }^{60}$ using the following extra packages: bbmle ${ }^{61}, D H A R M a^{62}$, dplyr $^{63}$, ggplot $2^{64}$, lattice $^{65}$, latticeExtra ${ }^{66}, \operatorname{lme}^{67}{ }^{6}$ oce $e^{68}$, and tidyr $r^{69}$.

We followed a widely used two-step model selection protocol ${ }^{70}$, starting with a full model, with all fixed effects, but alternative combinations of the random effects, to determine the random-effect structure that is best supported by the data. We selected models using corrected Akaike Information Criteria (AICc). We then kept the random-effect structure from the best supported model and fitted the following models to identify the best supported fixed-effect structure: (1) all environmental variables, except light intensity; (2) all environmental variables, including a linear effect for light intensity; (3) all environmental variables, including a quadratic effect for light intensity; (4) no fixed effects (null model). We included a model with quadratic effect for light intensity to model a scenario where intermediate light intensities produce larger visitation rates, as stated in our second hypothesis. Then, we used the AICc to again identify which relation between light intensity and bee activity (if any) was best supported by the data. We calculated $95 \%$ confidence intervals for the estimated fixed effect of each predictor variable in the best model to evaluate how strong the effect of light intensity was compared with other factors. Our hypotheses predicted a quadratic relationship of visitation rate and light intensity, with a peak of activity at intermediate light intensities during twilight. We also expected that the effect of light intensity would be larger than the effects estimated for the other environmental predictors.

We checked if the best model fulfilled the main assumptions of GLMMs using scalar (quantile) residuals created by a simulation-based approach implemented in the package $D H A R M a^{62}$. We checked the uniformity of scaled residuals and plotted residuals against explanatory variables. We also checked zero-inflation (Fig. S17). Validation occurred after the model selection and before its interpretation. We also checked if foraging activity increased throughout the season with a linear regression between date and the average visitation rate for all minutes and trees on each night (Fig. S8).

\section{Data availability}

All data generated or analysed during this study are included in this published article (and its Supplementary Information files).

Received: 13 May 2020; Accepted: 12 August 2020

Published online: 18 September 2020 


\section{References}

1. Michener, C. D. The Bees of the World (The Johns Hopkins University Press, Baltimore, 2007).

2. Wcislo, W. T. \& Tierney, S. M. Behavioural environments and niche construction: The evolution of dim-light foraging in bees. Biol. Rev. 84, 19-37 (2009).

3. Warrant, E. J. Nocturnal bees. Curr. Biol. 17, 991-992 (2007).

4. Warrant, E. J. Seeing in the dark: Vision and visual behaviour in nocturnal bees and wasps. J. Exp. Biol. 211, 1737-1746 (2008).

5. Somanathan, H., Borges, R. M., Warrant, E. J. \& Kelber, A. Visual ecology of Indian carpenter bees I: Light intensities and flight activity. J. Comp. Physiol. A Neuroethol. Sensory Neural Behav. Physiol. 194, 97-107 (2008).

6. Somanathan, H., Saryan, P. \& Balamurali, G. S. Foraging strategies and physiological adaptations in large carpenter bees. J. Comp. Physiol. A Neuroethol. Sensory Neural Behav. Physiol. 205, 387-398 (2019).

7. Engel, M. S. Classification of the bee tribe Augochlorini (Hymenoptera: Halictidae). Bull. Am. Museum Nat. Hist. 250, 1-90 (2000).

8. Silveira, F. A., Melo, G. A. R. \& Almeida, E. A. B. Abelhas Brasileiras: Sistemática e Identificação (Fundação Araucária, Belo Horizonte, 2002).

9. Wcislo, W. T. et al. The evolution of nocturnal behaviour in sweat bees, Megalopta genalis and M. ecuadoria (Hymenoptera: Halictidae): An escape from competitors and enemies?. Biol. J. Linn. Soc. 83, 377-387 (2004).

10. Carvalho, A. T., Maia, A. C. D., Ojima, P. Y., dos Santos, A. A. \& Schlindwein, C. Nocturnal bees are attracted by widespread floral scents. J. Chem. Ecol. 38, 315-318 (2012)

11. Janzen, D. Notes on nesting and foraging behavior of Megalopta (Hymenoptera: Halictidae) in Costa Rica. J. Kansas Entomol. Soc. 41, 342-350 (1968).

12. Roberts, R. B. Biology of the crepuscular bee Ptiloglossa guinnae N. sp. with notes on associated bees, mites, and yeasts. J. Kansas Entomol. Soc. 44, 283-294 (1971).

13. Rozen, J. G. Nesting biology of Diphaglossine bees (Hymenoptera, Colletidae). Am. Museum Novit. 2786, 1-33 (1984).

14. Santos, L. M., Tierney, S. M. \& Wcislo, W. T. Nest descriptions of Megalopta aegis (Vachal) and M. guimaraesi Santos \& Silveira (Hymenoptera, Halictidae) from the Brazilian Cerrado. Rev. Bras. Entomol. 54, 332-334 (2010).

15. Sarzetti, L., Genise, J., Sanchez, M. V., Farina, J. \& Molina, A. Nesting behavior and ecological preferences of five Diphaglossinae species (Hymenoptera, Apoidea, Colletidae) from Argentina and Chile. J. Hymenopt. Res. 33, 63-82 (2013).

16. Wolda, H. \& Roubik, D. W. Nocturnal bee abundance and seasonal bee activity in a Panamanian forest. Ecology 67, 426-433 (1986).

17. Linsley, E. G. \& Cazier, M. A. Some competitive relationships among matinal and late afternoon foraging activities of Caupolicanine bees in Southeastern Arizona (Hymenoptera, Colletidae). J. Kansas Entomol. Soc. 43, 251-261 (1970).

18. Roulston, T. H. Hourly capture of two species of Megalopta (Hymenoptera: Apoidea; Halictidae) at black lights in Panama with notes on nocturnal foraging by bees. J. Kansas Entomol. Soc. 70, 189-196 (1997).

19. Smith, A. R., López Quintero, I. J., Moreno Patiño, J. E., Roubik, D. W. \& Wcislo, W. T. Pollen use by Megalopta sweat bees in relation to resource availability in a tropical forest. Ecol. Entomol. 37, 309-317 (2012).

20. Dafni, A., Kevan, P. G. \& Husband, B. C. Practical Pollination Biology (Enviroquest Ltd., Cambridge, 2005).

21. Somanathan, H. \& Borges, R. M. Nocturnal pollination by the carpenter bee Xylocopa tenuiscapa (Apidae) and the effect of floral display on fruit set of Heterophragma quadriloculare (Bignoniaceae) in India. Biotropica 33, 78-89 (2001).

22. Contrera, F. A. L. \& Nieh, J. C. The effect of ambient temperature on forager sound production and thoracic temperature in the stingless bee, Melipona panamica. Behav. Ecol. Sociobiol. 61, 887-897 (2007).

23. Willmer, P. G. Thermal constraints on activity patterns in nectar-feeding insects. Ecol. Entomol. 8, 455-469 (1983).

24. Linsley, E. G. The ecology of solitary bee. Hilgardia 27, 543-599 (1958).

25. Figueiredo-Mecca, G., Bego, L. R. \& Nascimento, F. S. Foraging behavior of Scaptotrigona depilis (Hymenoptera, Apidae, Meliponini) and its relationship with temporal and abiotic factors. Sociobiology 60, 277-282 (2013).

26. Streinzer, M., Huber, W. \& Spaethe, J. Body size limits dim-light foraging activity in stingless bees (Apidae: Meliponini). J. Comp. Physiol. A 202, 643-655 (2016).

27. Linsley, E. G. Temporal patterns of flower visitation by solitary bees, with particular reference to the southwestern United States. J. Kansas Entomol. Soc. 51, 531-546 (1978).

28. Borges, R. M., Somanathan, H. \& Kelber, A. Patterns and processes in nocturnal and crepuscular pollination services. Q. Rev. Biol. 91, 389-418 (2016).

29. Warrant, E. J. Seeing better at night: Life style, eye design and the optimum strategy of spatial and temporal summation. Vis. Res. 39, 1611-1630 (1999).

30. Warrant, E. J. et al. Nocturnal vision and landmark orientation in a tropical halictid bee. Curr. Biol. 14, 1309-1318 (2004).

31. Warrant, E. Vision in the dimmest habitats on Earth. J. Comp. Physiol. A Neuroethol. Sensory Neural Behav. Physiol. 190, $765-789$ (2004).

32. Warrant, E. \& Dacke, M. Vision and visual navigation in nocturnal insects. Annu. Rev. Entomol. 56, 239-254 (2011).

33. Rozenberg, G. V. Twilight (Springer, New York, 1966).

34. O'Carroll, D. C. \& Warrant, E. J. Vision in dim light: Highlights and challenges. Philos. Trans. R. Soc. B Biol. Sci. 372, 20160062 (2017).

35. Smith, A. R., Kitchen, S. M., Toney, R. M. \& Ziegler, C. Is nocturnal foraging in a tropical bee an escape from interference competition?. J. Insect Sci. 17, 1-7 (2017).

36. Kapustjanskij, A., Streinzer, M., Paulus, H. F. \& Spaethe, J. Bigger is better: implications of body size for flight ability under different light conditions and the evolution of alloethism in bumblebees. Funct. Ecol. 21, 1130-1136 (2007).

37. Lorenzi, H. Brazilian Trees: A Guide to the Identification and Cultivation of Brazilian Native Trees (Instituto Plantarum de Estudos da Flora, Nova Odessa, 2002).

38. Cordeiro, G. D., Pinheiro, M., Dötterl, S. \& Alves-dos-Santos, I. Pollination of Campomanesia phaea (Myrtaceae) by night-active bees: A new nocturnal pollination system mediated by floral scent. Plant Biol. 19, 132-139 (2017).

39. Kelber, A. et al. Light intensity limits foraging activity in nocturnal and crepuscular bees. Behav. Ecol. 17, 63-72 (2006).

40. Polatto, L. P., Chaud-Netto, J. \& Alves-Junior, V. V. Influence of abiotic factors and floral resource availability on daily foraging activity of bees. J. Insect Behav. 27, 593-612 (2014).

41. Willis, D. S. \& Kevan, P. G. Foraging dynamics of Peponapis pruinosa (Hymenoptera: Anthophoridae) on pumpkin (Cucurbita pepo) in Southern Ontario. Can. Entomol. 127, 167-175 (1995).

42. Wcislo, W. T. \& Cane, J. H. Floral resource utilization by solitary bees (Hymenoptera: Apoidea) and exploitation of their stored foods by natural enemies. Annu. Rev. Entomol. 41, 257-286 (1996).

43. Bellusci, S. \& Marques, M. D. Circadian activity rhythm of the foragers of a eusocial bee (Scaptotrigona aff depilis, Hymenoptera, Apidae, Meliponinae) outside the nest. Biol. Rhythm Res. 32, 117-124 (2001).

44. Bloch, G., Bar-Shai, N., Cytter, Y. \& Green, R. Time is honey: Circadian clocks of bees and flowers and how their interactions may influence ecological communities. Philos. Trans. R. Soc. B Biol. Sci. 372, 20160256 (2017).

45. Enright, J. T. Ecological aspects of endogenous rhythmicity. Annu. Rev. Ecol. Evol. Syst. 1, 221-238 (1970).

46. Shelly, T. E., Villalobos, E. M., Buchmann, S. L. \& Cane, J. H. Temporal patterns of floral visitation for two bee species foraging on Solanum. J. Kansas Entomol. Soc. 66, 319-327 (1993). 
47. Gottlieb, D., Keasar, T., Shmida, A. \& Motro, U. Possible foraging benefits of bimodal daily activity in Proxylocopa olivieri (Lepeletier) (Hymenoptera: Anthophoridae). Environ. Entomol. 34, 417-424 (2005).

48. Franco, E. L. \& Gimenes, M. Pollination of Cambessedesia wurdackii in Brazilian campo rupestre vegetation, with special reference to crepuscular bees. J. Insect Sci. 11, 1-13 (2011).

49. Oliveira, F. S., Ribeiro, M. H. M., Nunez, C. V. \& de Albuquerque, M. C. Flowering phenology of Mouriri guianensis (Melastomataceae) and its interaction with the crepuscular bee Megalopta amoena (Halictidae) in the restinga of Lençóis Maranhenses National Park, Brazil. Acta Amaz. 46, 281-290 (2016).

50. Willmer, P. \& Stone, G. Temperature and water relations in desert bees. J. Therm. Biol. 22, 453-465 (1997).

51. Krug, C. et al. Nocturnal bee pollinators are attracted to guarana flowers by their scents. Front. Plant Sci. 9, 1072 (2018).

52. Siqueira, E. et al. Pollination of Machaerium opacum (Fabaceae) by nocturnal and diurnal bees. Arthropod. Plant. Interact. 12, 633-645 (2018).

53. Orbán, L. L. \& Plowright, C. M. S. Getting to the start line: How bumblebees and honeybees are visually guided towards their first floral contact. Insectes Soc. 61, 325-336 (2014).

54. Burger, H., Dotterl, S. \& Ayasse, M. Host-plant finding and recognition by visual and olfactory floral cues in an oligolectic bee. Funct. Ecol. 24, 1234-1240 (2010).

55. Milet-Pinheiro, P., Ayasse, M., Schlindwein, C., Dobson, H. E. M. \& Dötterl, S. Host location by visual and olfactory floral cues in an oligolectic bee: Innate and learned behavior. Behav. Ecol. 23, 531-538 (2012).

56. Kantsa, A. et al. Community-wide integration of floral colour and scent in a Mediterranean scrubland. Nat. Ecol. Evol. 1, 1502-1510 (2017).

57. Peel, M. C., Finlayson, B. L. \& McMahon, T. A. Updated world map of the Koppen-Geiger climate classification. Hydrol. Earth Syst. Sci. 11, 1633-1644 (2007).

58. Michener, C. D. \& Lange, R. B. Observations on the behavior of Brasilian halictid bees, III. Univ. Kansas Sci. Bull. 39, 473-505 (1958).

59. Meinel, A. B. \& Meinel, M. P. Sunsets, Twilights, and Evening Skies (Cambridge University, Cambridge, 1991).

60. R Core Team, R. R: A language and environment for statistical computing. R Found. Stat. Comput. Vienna, Austria. www.R-proje ct.org (2017). Accessed 15 Dec 2017.

61. Bolker, B. \& R Core Team, R. bbmle: Tools for general maximum likelihood estimation. R Packag. version 1.0.20. https://CRAN.Rproject.org/package=bbmle (2017). Accessed 15 Dec 2017.

62. Hartig, F. DHARMa: Residual diagnostics for hierarchical (multi-level/mixed) regression models. $R$ Packag. version 0.1.5. https:// CRAN.R-project.org/package=DHARMa (2017). Accessed 15 Dec 2017.

63. Wickham, H., Francois, R., Henry, L. \& Müller, K. dplyr: A grammar of data manipulation. R Packag. version 0.7.4. https:// CRAN.R-project.org/package=dplyr (2017). Accessed 15 Dec 2017.

64. Wickham, H. ggplot2: Elegant Graphics for Data Analysis (Springer, New York, 2009).

65. Sarkar, D. Lattice: Multivariate data visualization with R. $R$ Packag. version 0.20-38. https://CRAN.R-project.org/package=lattice (2008). Accessed 15 Dec 2017.

66. Sarkar, D. \& Andrews, F. latticeExtra: Extra graphical utilities based on lattice. R Packag. version 0.6-28. https://CRAN.R-proje ct.org/package=latticeExtra (2016). Accessed 15 Dec 2017.

67. Bates, D., Maechler, M., Bolker, B. \& Walker, S. Fitting linear mixed-effects models using lme4. J. Stat. Softw. 67, 1-48 (2015).

68. Kelley, D. \& Richards, C. oce: Analysis of oceanographic data. R Packag. version 0.9-22. https://CRAN.R-project.org/package=oce (2017). Accessed 15 Dec 2017.

69. Wickham, H. \& Henry, L. tidyr: Easily tidy data with 'spread()' and 'gather()' functions. R Packag. version 0.8.0. https://CRAN.Rproject.org/package=tidyr (2018). Accessed 15 Dec 2017.

70. Zuur, A. F., Ieno, E. N., Walker, N. J., Saveliev, A. A. \& Smith, G. M. Mixed Effects Models and Extensions in Ecology with R (Springer, New York, 2009).

\section{Acknowledgements}

We thank Priscila S. Oliveira, William Sabino, and Ana Carolina Oliveira for help in the field work; Mr Alexandre and family for permission to work in their cambuci orchards; Marco A. Marques and Sérgio T. Meirelles for technical support on field devices; Sebastian Koethe, Sarah Banysch, and Klaus Lunau for help in collecting reflectance data; Paulo R. Guimarães Jr and Francismeire J. Telles for helpful comments. CAPES and CNPq supported R.L. (133965/2017-1), G.D.C. (153561/2016-5), P.I.P. (310885/2017-5), C.S. (436095/2018-1), and I.A.S. (401466/2014-0). Swedish Research Council supported E.J.W. (VR-2016-04014).

\section{Author contributions}

R.L., G.D.C., C.S., P.I.P. and I.A.S. designed the study. R.L., G.D.C. and E.J.W. collected the data. R.L. and E.J.W. analysed the light intensity data. R.L. and P.I.P. performed model fitting, selection, and validation, and analysed the other data with the remaining authors. R.L. prepared figures and led manuscript writing, with contributions of all authors.

\section{Funding}

Open access funding provided by Lund University.

\section{Competing interests}

The authors declare no competing interests.

\section{Additional information}

Supplementary information is available for this paper at https://doi.org/10.1038/s41598-020-72047-x.

Correspondence and requests for materials should be addressed to R.L., G.D.C. or E.J.W.

Reprints and permissions information is available at www.nature.com/reprints.

Publisher's note Springer Nature remains neutral with regard to jurisdictional claims in published maps and institutional affiliations. 
(c) (i) Open Access This article is licensed under a Creative Commons Attribution 4.0 International cc) License, which permits use, sharing, adaptation, distribution and reproduction in any medium or format, as long as you give appropriate credit to the original author(s) and the source, provide a link to the Creative Commons license, and indicate if changes were made. The images or other third party material in this article are included in the article's Creative Commons license, unless indicated otherwise in a credit line to the material. If material is not included in the article's Creative Commons license and your intended use is not permitted by statutory regulation or exceeds the permitted use, you will need to obtain permission directly from the copyright holder. To view a copy of this license, visit http://creativecommons.org/licenses/by/4.0/.

(C) The Author(s) 2020 